\title{
Finite Volume Numerical Analysis of the Thermal Property of Cellular Concrete Based on Two and Three Dimensional X-ray Computerized Tomography Images
}

\author{
She Wei, Yang Yonggan, Xie Deqing, and Zhang Yunsheng \\ Jiangsu Key laboratory for Construction Materials, Southeast University \\ She Wei \\ Concrete Technology Unit, Division of Civil Engineering, University of Dundee
}

\begin{abstract}
Cellular concrete is one kind of lightweight concrete, which are widely used in thermal insulation engineering project. In this study, a three dimensional (2D and 3D) finite-volume-based models was developed for analyzing the heat transfer mechanisms through the porous structures of cellular concretes under steady-state heat transfer condition and also for investigating the differences between 2D and 3D modeling results. 2D and 3D reconstructed pore networks were generated from the microstructural information measured by a 3D image captured by $\mathrm{X}$-ray computerized tomography (X-CT). In addition, the 3D-computed value of the effective thermal conductivity was found to be in better agreement with the measured value, in comparison with that computed on the basis of 2D cross-sectional images. Finally, the thermal conductivity computed for different porous 3D networks of cellular concretes were compared with those obtained from 2D computations, revealing the differences between 2D and 3D image-based modeling: a correlation was thus derived between the results computed with 3D and 2D models.
\end{abstract}

Keywords: finite volume method, thermal conductivity, image-based modeling, cellular concrete, guarded hot-plate method.

\section{INTRODUCTION}

In recent years, builders around the world have become increasingly interested in using cellular concrete in their projects. This interest comes from the decreasing volume of load-bearing elements, as well as the superior thermal properties of lightweight concrete compared with conventional concrete. Regarding the latter advantage, dry densities of $300-500 \mathrm{~kg} / \mathrm{m}^{3}$ are usually applied. As there are no strict requirements to strength characteristics, thermal performance plays the more domain role (Aldridge, 2000; Jones \& McCarthy, 2005b; Kearsley \& Mostert 2005b; Narayanan \& Ramamurthy, 2000; Esmaily \& Nuranian, 2012). Therefore, the accurate determination of the effective thermal conductivity, ke is the essential for engineering application. Furthermore, it is possible to design the properties of cellular concrete to meet the construction requirement by varying material parameters such as cement paste composition, bubble size, and volume friction. To this end, an accurate evaluation of the relationship between the microstructure and thermal transfer properties of such porous lightweight building materials is required. Determination of the relationship between the microstructure and effective thermal property of porous materials can be accomplished either experimentally (Mydin \& Wang, 2012; Nooraini,
Ismail, \& Ahmad Mujahid, 2009) or analytically by assuming simplified geometries (Wiener, 1904; Hashin \& Shtrikman, 1962; Landauer, 1952; Russell, 1935; Glicksmann \& Schuetz, 1994; Ahern, Verbist, Weaire, Phelan, \& Fleurent, 2005; Bhattacharya, Calmidi, \& Mahajan, 2002). The former approach is expensive and time consuming, and the validity of the results is usually limited to the experimental conditions. The latter approach is limited by the validity of the underlying assumptions for the complex geometry. Some of these limitations can be overcome by the combined experimental-numerical technique presented in this article.

This study aimed at developing $2 \mathrm{D}$ and $3 \mathrm{D}$ imagebased finite volume models to analyze the heat transfer mechanisms through the porous structure of cellular concrete under steady-state condition.

The microstructure of cellular concrete was quantitatively characterized by a three dimensional-Xray computerized tomography technology (3D-XCT) considering two phases, namely the pores and the matrix. The numerical results were validated by comparison with experimental results. Finally, comparisons of the effective thermal conductivities obtained from the $3 \mathrm{D}$ image, $2 \mathrm{D}$ cross-sectional 
images revealed some differences between 2D and 3D modeling.

\section{THERMAL CONDUCTIVITY MEASUREMENT}

The measurement apparatus used in this study is a guarded hot-plate that was designed based on the standards for steady-state measurement (ISO 8990:1994, 2006; EN 12939:2000, 2000; EN 12664:2001, 2001). The guarded hot-plate method (GHP) (see Figure 1) establishes a one-dimensional heat flow through a pair of specimens by reducing undesired lateral heat flows to negligible proportions (Yesilata \& Turgut, 2007; Zarr, 2001). The apparatus presented here was adapted from the one used to measure U-value of a wall according to the standard for steady-state measurement ISO 8990 (Wei, Yiqiang, Yunsheng, \& Jones, 2013).

Our system is able to host materials with a thickness ranging from 10 to $100 \mathrm{~mm}$. Figure 1 shows the collocation of specimens between hot and cold slabs. Heat is supplied electrically at a known rate to the hot-slab, maintaining a constant temperature difference between the hot and cold slabs. The temperature differences are controlled by means of thermocouples on the slabs' surfaces. Energy consumed is registered by means of an external wattmeter that analyzes and transmits the data to a computer. The temperature is continuously measured and controlled with a proportional-integralDerivative (PID) regulator to maintain the required temperature gradient. The guarded plates play role of thermal barriers to secure the one dimensional heat flow from the main heater to the cold plate, which makes it possible to measure the value of $Q$ exactly.

In our experiments, the specimens and both cold and hot-slabs initially are at the same temperature, and then, at the beginning of the experiment, the temperature of the cold plate is suddenly lowered from 313 to $273 \mathrm{~K}$. The humidity of the room was controlled and maintained lower than $50 \%$.

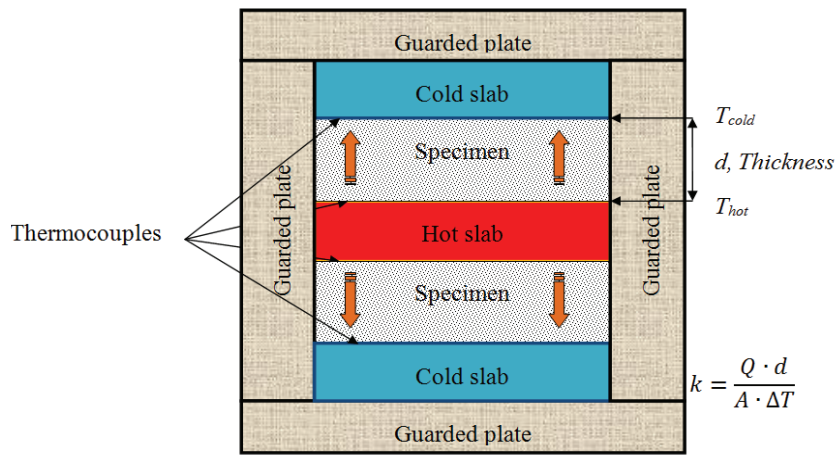

Figure 1. Experimental apparatus. The guarded hot-plate method establishes one dimensional heat flow through a pair of specimens. The guarded plate was made of expanded polystyrene (EPS).
The box was placed in a hot chamber operating at controlled fixed temperatures, humidity, and air flow conditions. Temperature and relative humidity sensors are positioned at several points to measure the corresponding air conditions.

After 28 days' sealed curing, the specimens of cellular concrete $(300 \mathrm{~mm} \times 300 \mathrm{~mm} \times 30 \mathrm{~mm})$ were oven dried at a temperature of $80^{\circ} \mathrm{C}$ until constant mass (approximately 4 days). This was done to eliminate any moisture retained in the slabs, as it would have had effect on the conductivity results (Russell, 1935).

Heat was allowed to flow between the two plates until the system stabilized. The maximum time allowed for the samples to stabilize was about $3 \mathrm{~h}$. Then the thermal conductivity based on GHP method can be calculated using the Fourier heat flow equation:

$$
k=\frac{Q \cdot d}{C \cdot \Delta T}
$$

Where $k$ is the effective thermal conductivity of tested sample. $Q$ is the time rate of heat flow. $d$ is the thickness of the tested sample. $C$ and $\Delta T$ are crosssectional area and temperature difference across the sample, respectively. This test method is especially useful for generating thermal data on deformable flexible specimens and has been considered as a primary technique for precise thermal conductivity measurement. The expanded uncertainty of thermal conductivity measurements considering both random and systematic errors was evaluated to be $2 \%$ with a confidence level of $95 \%$.

\section{FINITE VOLUME NUMERICAL MODEL}

The implementation of a finite-volume method for estimating the effective thermal conductivity of porous concrete was first proposed by Wei et al. (2013). The method is based on the analysis of the temperature distribution in the foam microstructure by considering the governing differential equation of steady-state heat conduction without internal heat generation. The model simulates steady-state thermal conductivity measurement apparatus as discussed above. The piece considered is a slab of porous material with perfectly insulated sides which is sandwiched between two slabs of non-porous solid maintained at temperatures $T_{\text {hot }}$ and $T_{\text {cold }}$ (Figure 2). The steady-state heat conduction equation expresses the heat balance at each point of the two-phase porous material.

Additionally, conduction through the solid phase, conduction through the gas phase, convection of the gas and radiation are generally the main mechanisms which may contribute to the thermal conductivity of a cellular material (Gibson \& Ashby, 1997). Taking into account previous works by Skochdopole (1961) and 
Lu and Chen (1999), the heat transfer by convection does not exist for cell diameters smaller than $4 \mathrm{~mm}$, and the experimental temperature for ETC is not very high. Therefore, only the conduction mechanism of two phases is considered in this study.

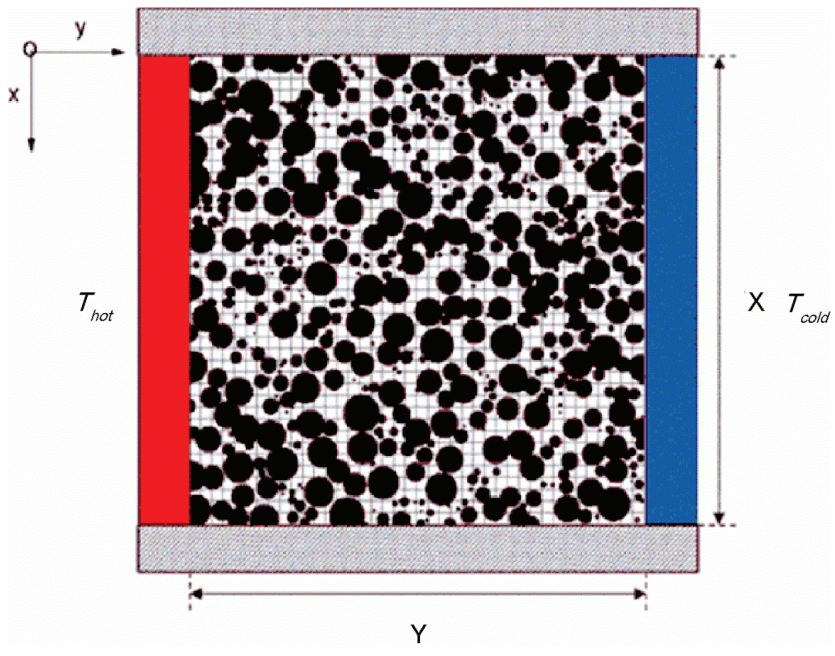

Figure 2. 2D illustration of the principle of the ETC computation.

\subsection{D numerical model}

In the 2D model, the steady thermal transfer equation can be expressed as follow:

$$
\frac{\partial}{\partial x}\left(\lambda_{i, j} \frac{\partial T}{\partial x}\right)+\frac{\partial}{\partial y}\left(\lambda_{i, j} \frac{\partial T}{\partial y}\right)=0
$$

In which $\lambda_{\mathrm{i}, \mathrm{j}}$ is the thermal conductivity and $T$ is the temperature. With regards to a 5-point integration formula, a schematic view of a cell of the domain (i.e., a pixel of the binary image) and its four neighbor is presented in Figure 3. For the particular case of square pixels, the above equation can be discretized as follows:

$$
\begin{aligned}
& -(T(i+1, j)-T(i, j)) \cdot \lambda(i+1 / 2, j) \\
& +(T(i, j)-T(i-1, j)) \cdot \lambda(i-1 / 2, j) \\
& -(T(i, j+1)-T(i, j)) \cdot \lambda(i, j+1 / 2) \\
& +(T(i, j)-T(i, j-1)) \cdot \lambda(i, j-1 / 2)=0
\end{aligned}
$$

In which $\lambda_{(\mathrm{i}+1 / 2, \mathrm{j})}$ represents the thermal conductivity between cell centres $(i, j)$ and $(i+1, j)$, and can be expressed as:

$$
\lambda(i+1 / 2, j)=2 /\left(\frac{1}{\lambda(i, j)}+\frac{1}{\lambda(i+1, j)}\right)
$$

The thermal conductivity $\lambda(i, j)$ is assigned to each pixel depending on its corresponding materials (e.g., cement paste for the white pixels and pores for the black ones). For the considered images, the boundary conditions are settled by applying a constant temperature on the

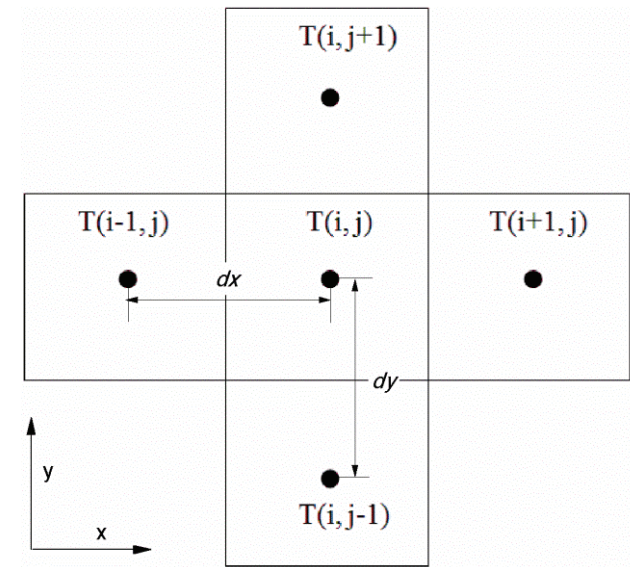

Figure 3. Schematic view of a cell in 2D model, including its four neighbors.

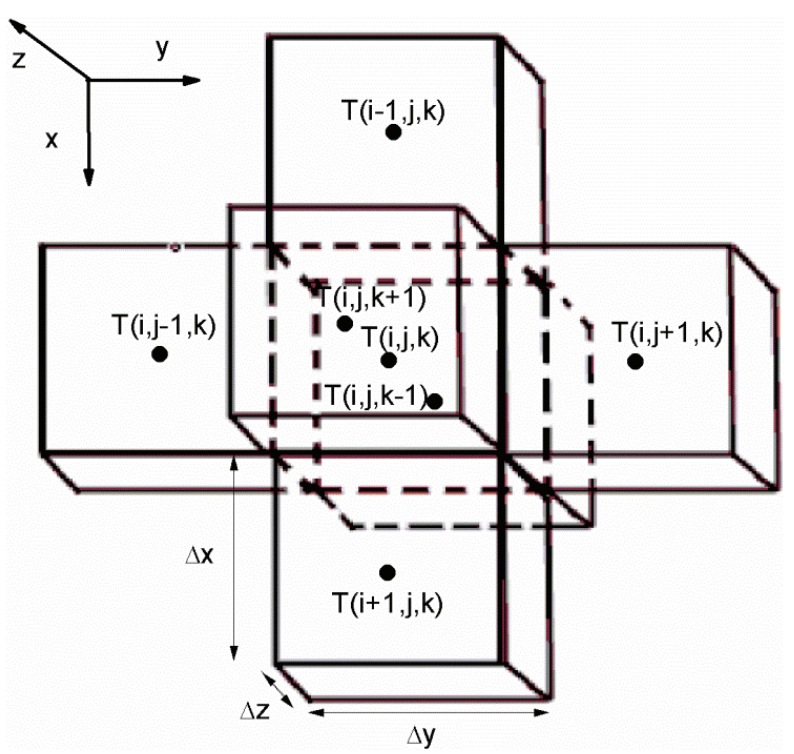

Figure 4. Schematic view of a cell in 3D model, including its six neighbors.

left side edge (e.g., $313.5 \mathrm{~K}$ ) as well as on the right side (e.g., $273.5 \mathrm{~K}$ ), and a zero flux is applied for the other two edges (i.e., top and bottom). The corresponding mathematical expression is

$$
\left.\frac{\partial T}{\partial x}\right|_{x=0}=\left.\frac{\partial T}{\partial x}\right|_{x=x}=0
$$

\subsection{D numerical model}

Regarding the three dimensional model, a lattice of the domain is shown in Figure 4. The corresponding steady thermal transfer equation can be expressed as:

$$
\frac{\partial}{\partial x}\left(\lambda_{i, j, k} \frac{\partial T}{\partial x}\right)+\frac{\partial}{\partial y}\left(\lambda_{i, j, k} \frac{\partial T}{\partial y}\right)+\frac{\partial}{\partial z}\left(\lambda_{i, j, k} \frac{\partial T}{\partial z}\right)=0
$$


In which $\lambda_{i j k}$ is also the thermal conductivity and $T$ is the temperature. For the case of cubic voxels, the above equation can be discretized as follows:

$$
\begin{aligned}
& -(T(i+1, j, k)-T(i, j, k)) \cdot \lambda(i+1 / 2, j, k) \\
& +(T(i, j, k)-T(i-1, j, k)) \cdot \lambda(i-1 / 2, j, k) \\
& -(T(i, j+1, k)-T(i, j, k)) \cdot \lambda(i, j+1 / 2, k) \\
& +(T(i, j, k)-T(i, j-1, k)) \cdot \lambda(i, j-1 / 2, k) \\
& -(T(i, j, k+1)-T(i, j, k) \cdot \lambda(i, j, k+1 / 2) \\
& +(T(i, j, k)-T(i, j, k-1)) \cdot \lambda(i, j, k-1 / 2)=0
\end{aligned}
$$

Where $\lambda(i+1 / 2, j, k)$ also represents the thermal conductivity between lattices centers $(i, j, k)$ and $(i+1, j, k)$, and can be expressed as:

$$
\lambda(i+1 / 2, j, k)=2 /\left(\frac{1}{\lambda(i, j, k)}+\frac{1}{\lambda(i+1, j, k)}\right)
$$

The thermal conductivity $\lambda(i, j, k)$ is assigned to the voxels in the similar way as for $2 \mathrm{D}$ model. In addition, a zero flux boundary condition was applied for the other four lateral faces. The corresponding mathematical expression of boundary condition can be expressed as:

$$
\begin{aligned}
& \left.\frac{\partial T}{\partial x}\right|_{x=0}=\left.\frac{\partial T}{\partial x}\right|_{x=x}=0 \\
& \left.\frac{\partial T}{\partial z}\right|_{z=0}=\left.\frac{\partial T}{\partial z}\right|_{z=z}=0
\end{aligned}
$$

\subsection{D and 3D sparse matrix}

Applying the Equations (3) and (7) to all the cells in 2D and 3D models respectively, we will have $P$ equations $\left(P_{2 \mathrm{D}}=X \times(Y-2), P_{3 \mathrm{D}}=X \times(Y-2) \times Z\right)$ for $P$ unknown cell temperatures. Both Equations (3) and (7) can be written in a matrix form as

$$
\tilde{\Gamma} \vec{T}=\vec{S}
$$

Where the matrix $\tilde{\Gamma}$ is a sparse multi-diagonal symmetrical matrix and $\vec{T}$ is a vector of $P$ components which correspond to the unknown cell temperatures. The right-hand side vector $\vec{S}$ has a length $P$ and is composed of zero values with the exception of the edge elements ( $y=0$ and $y=Y$ ) where the boundary temperatures are imposed (here temperatures of 273.5 and $313.5 \mathrm{~K}$, respectively).

As an illustration, Equation (3) can be written for a $3 \times 4$ two-dimensional network (see Figure 5) as

$$
\begin{aligned}
& \left(\begin{array}{cccccc}
D_{11} & V_{11} & 0 & H_{12} & 0 & 0 \\
V_{11} & D_{21} & V_{21} & 0 & H_{22} & 0 \\
0 & V_{21} & D_{31} & 0 & 0 & H_{32} \\
H_{12} & 0 & 0 & D_{12} & V_{12} & 0 \\
0 & H_{22} & 0 & V_{12} & D_{22} & V_{22} \\
0 & 0 & H_{32} & 0 & V_{22} & D_{32}
\end{array}\right)\left(\begin{array}{c}
T_{11} \\
T_{21} \\
T_{31} \\
T_{12} \\
T_{22} \\
T_{32}
\end{array}\right) \\
& =T_{\text {hot }}\left(\begin{array}{c}
-H_{11} \\
-H_{21} \\
-H_{31} \\
0 \\
0 \\
0
\end{array}\right)+T_{\text {cold }}\left(\begin{array}{c}
0 \\
0 \\
-H_{13} \\
-H_{23} \\
-H_{33}
\end{array}\right)
\end{aligned}
$$

While for a $3 \times 4 \times 2$ three-dimensional network (see Figure 6), Equation (7) can be written as

$$
\left(\begin{array}{cccccccccccc}
D_{111} & V_{111} & 0 & H_{121} & 0 & 0 & B_{111} & 0 & 0 & 0 & 0 & 0 \\
V_{111} & D_{211} & V_{211} & 0 & H_{221} & 0 & 0 & B_{211} & 0 & 0 & 0 & 0 \\
0 & V_{211} & D_{311} & 0 & 0 & H_{321} & 0 & 0 & B_{311} & 0 & 0 & 0 \\
H_{121} & 0 & 0 & D_{121} & V_{121} & 0 & 0 & 0 & 0 & B_{121} & 0 & 0 \\
0 & H_{221} & 0 & V_{121} & D_{221} & V_{221} & 0 & 0 & 0 & 0 & B_{221} & 0 \\
0 & 0 & H_{321} & 0 & V_{221} & D_{321} & 0 & 0 & 0 & 0 & 0 & B_{321} \\
B_{111} & 0 & 0 & 0 & 0 & 0 & D_{112} & V_{112} & 0 & H_{122} & 0 & 0 \\
0 & B_{211} & 0 & 0 & 0 & 0 & V_{112} & D_{212} & V_{212} & 0 & H_{222} & 0 \\
0 & 0 & B_{311} & 0 & 0 & 0 & 0 & V_{212} & D_{312} & 0 & 0 & H_{322} \\
0 & 0 & 0 & B_{121} & 0 & 0 & H_{122} & 0 & 0 & D_{122} & V_{122} & 0 \\
0 & 0 & 0 & 0 & B_{221} & 0 & 0 & H_{222} & 0 & 0 & D_{222} & V_{222} \\
0 & 0 & 0 & 0 & 0 & B_{321} & 0 & 0 & H_{322} & 0 & V_{222} & D_{322}
\end{array}\right)\left(\begin{array}{c}
T_{111} \\
T_{211} \\
T_{311} \\
T_{121} \\
T_{221} \\
T_{321} \\
T_{112} \\
T_{212} \\
T_{312} \\
T_{122} \\
T_{222} \\
T_{322}
\end{array}\right)=T_{\square \square}\left(\begin{array}{c} 
\\
-H_{111} \\
-H_{211} \\
-H_{311} \\
0 \\
0 \\
-H_{112} \\
-H_{212} \\
-H_{312} \\
0 \\
0 \\
0 \\
-H_{131} \\
-H_{231} \\
-H_{331} \\
0 \\
0 \\
0 \\
-H_{132} \\
-H_{232} \\
-H_{332}
\end{array}\right)
$$




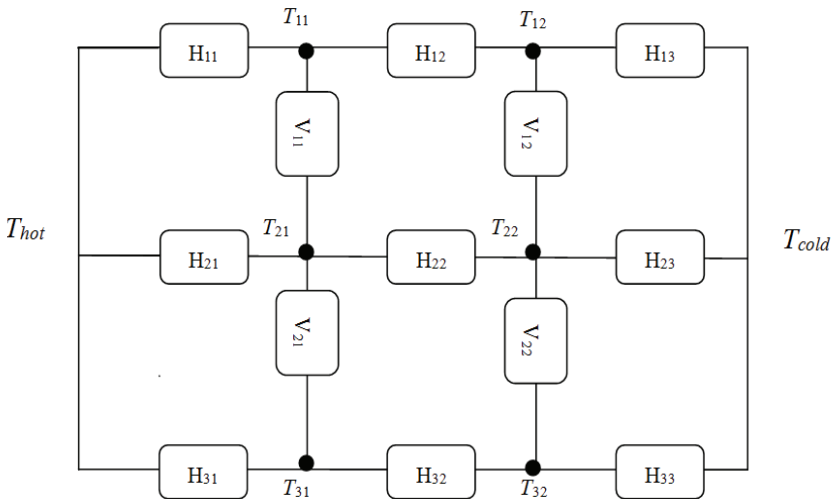

Figure 5. Schematic overview of a $2 \mathrm{D}$ thermal resistor network $(X \times Y=3 \times 4)$.

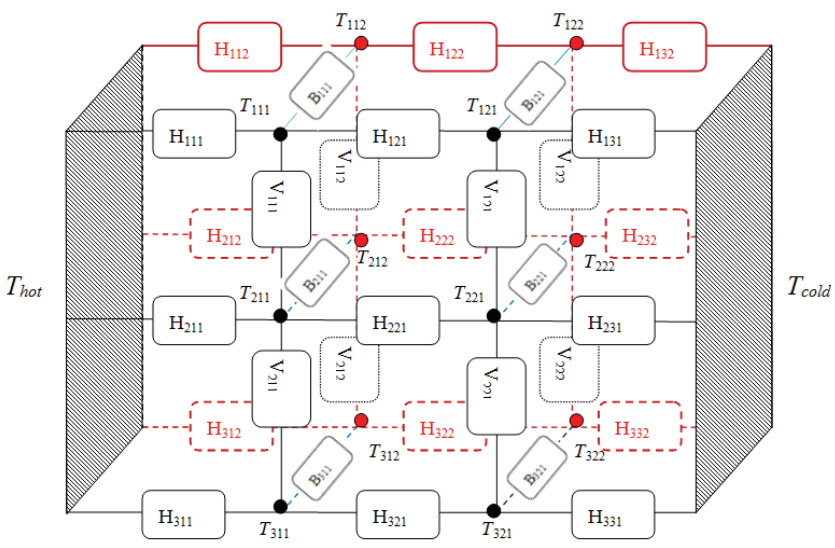

Figure 6. Schematic overview of a 3D thermal resistor network $(X \times Y \times Z=3 \times 4 \times 2)$.

The off-diagonal elements $V, H$, and $B$ of matrix $\tilde{\Gamma}$ correspond respectively to the thermal conductivity of the neighbor links in $x, y$-direction, and in the thickness direction $z$. The diagonal elements $D$ are the sum of the thermal conductivities of the neighbor links. Considering the case of large system of equations, the use of iterative algorithms is required to accelerate convergence and thus to reduce the required computational time. Once the temperature distribution over the lattice is know, it is possible to compute the heat fluxes $Q_{k}$ along the $y$ direction passing through each horizontal slice of the lattice (3D). These fluxes are equal for all the slices under steady-state conditions. Finally, the effective thermal conductivity $k_{\text {eff }}$ between the hot and cold slabs in 3D model can be simply obtained by:

$$
k_{\text {eff }}=\frac{Q_{\mathrm{k}} \cdot Y}{X \cdot Z} \times \frac{1}{T_{\text {hot }}-T_{\text {cold }}}
$$

Regarding the 2D model, the lattice number in $z$ direction is equal to 1 , thus $k_{\text {eff }}$ can be expressed as:

$$
k_{\text {eff }}=\frac{Q_{\mathrm{k}} \cdot Y}{X} \times \frac{1}{T_{\text {hot }}-T_{\text {cold }}}
$$

\section{THERMAL CONDUCTIVITY OF CEMENT PASTE AND PORES}

An experimental value of $0.5 \mathrm{~W} \mathrm{~m}^{-1} \mathrm{~K}^{-1}$, determined for a full dense sample (without air agent), was used for the thermal conductivity of the solid phase and this is consistent with other literature values (Fu \& Chung, 1999; Russell, 1935). Regarding the pores, it can be assumed as approximation that they contain trapped air for which the thermal conductivity may be estimated as $0.025 \mathrm{~W} \mathrm{~m}^{-1} \mathrm{~K}^{-1}$ at room temperature. The thermal conductivity of air tends to increase with temperature but the Knudsen effect (Collishaw \& Evans, 1994; Litovsky, Shapiro, \& Shavit, 1996) tends to decrease it on the other hand, so that the influence of micro pores in cement paste on the thermal conductivity of air was not considered in the present study.

\section{NUMERICAL RESULTS AND ANALYSIS}

\subsection{Benchmarks}

To validate the algorithm and the codes of the $2 \mathrm{D}$ and $3 \mathrm{D}$ models, the numerical predictions are compared with the theoretical solutions for two hypothetical structural cases: Parallel mode and series mode (see Table 1). The porous structures are formed in two phases and the thermal conductivities are 0.5 and $0.025 \mathrm{~W} \mathrm{~m}^{-1} \mathrm{~K}^{-1}$, respectively. To make comparison easily, the fractions of the two phases are equal so that the calculated effective thermal conductivity is $0.2625 \mathrm{~W} \mathrm{~m}^{-1} \mathrm{~K}^{-1}$ for parallel mode and $0.04762 \mathrm{~W} \mathrm{~m}^{-1} \mathrm{~K}^{-1}$ for series mode. Table 1 lists our predictions of the ETCs and the deviations from the simple analytical solutions as functions of the lattice number. It is interesting to note that the predicted values by $2 \mathrm{D}$ model are the same with corresponding $3 \mathrm{D}$ model. The reason for this is that the 3D structures of parallel mode and series mode are repetitive or symmetrical in the thickness direction ( $z$ ).

It is also clear that our predictions agree perfectly well with the theoretical solutions with the maximum deviation less than $2 \%$ when the lattice number is larger than 60 . The results validate the proposed algorithm and the boundary condition processing. A larger lattice number results in more accurate modeling result yet requires a higher computational cost. In the following modeling, lattice number is set to $80 \times 80 \times 80$ for $3 \mathrm{D}$ model and $500 \times 500$ for $2 \mathrm{D}$ model unless specified requirement.

\subsection{Computation of the thermal conductivity for the 2D and 3D models}

The thermal conductivity corresponding to each $3 \mathrm{D}-\mathrm{XCT}$ image was predicted by $3 \mathrm{D}$ modeling. $2 \mathrm{D}$ calculations were also carried out on cross-sections of the 3D-XCT real image (Figure 7). To obtain a 
reliable value, six cross-sections $(500 \times 500$ pixels $)$ of the 3D-XCT image were used and the results were then averaged. Examples of numerical modeling the temperature distribution of $3 \mathrm{D}$ and $2 \mathrm{D}$ structures are shown in Figures $8 \mathrm{a}$ and $8 \mathrm{~b}$, respectively.

The calculated results show that the $2 \mathrm{D}$ thermal conductivities were $0.121 \pm 0.04 \mathrm{~W} \mathrm{~m}^{-1} \mathrm{~K}^{-1}$ for the cross-sectional 2D images (shown in Table 2). On the other hand, the 3D predicted thermal conductivity was
$0.154 \mathrm{~W} \mathrm{~m}^{-1} \mathrm{~K}^{-1}$ (shown in Table 2), which was found to be in better agreement with the experimental result $\left(0.158 \mathrm{~W} \mathrm{~m}^{-1} \mathrm{~K}^{-1}\right)$. This consistent result indicates that the $3 \mathrm{D}$ reconstructed image can be representative of a real non-AAC in terms of thermal conductivity. It is also worth to point out that the $3 \mathrm{D}$ calculated thermal conductivity is higher than the $2 \mathrm{D}$ calculated one by about $15 \%$ for the same parameters to generate image.

Table 1. Predictions of effective thermal conductivities for two kinds of structures (parallel and series modes).

\begin{tabular}{|c|c|c|c|c|c|}
\hline \multicolumn{2}{|c|}{ Lattice number $(X \times Y \times Z)$} & \multicolumn{2}{|c|}{ Parallel mode } & \multicolumn{2}{|c|}{ Series mode } \\
\hline \multirow[t]{3}{*}{$2 \mathrm{D}$} & $10 \times 10$ & 0.2917 & 11.12 & 0.0529 & 11.09 \\
\hline & $60 \times 60$ & 0.2669 & 1.68 & 0.0484 & 1.64 \\
\hline & $80 \times 80$ & 0.2658 & 1.26 & 0.0482 & 1.21 \\
\hline \multirow[t]{3}{*}{$3 \mathrm{D}$} & $10 \times 10 \times 10$ & 0.2917 & 11.12 & 0.0529 & 11.09 \\
\hline & $60 \times 60 \times 60$ & 0.2669 & 1.68 & 0.0484 & 1.64 \\
\hline & $80 \times 80 \times 80$ & 0.2658 & 1.26 & 0.0482 & 1.21 \\
\hline
\end{tabular}

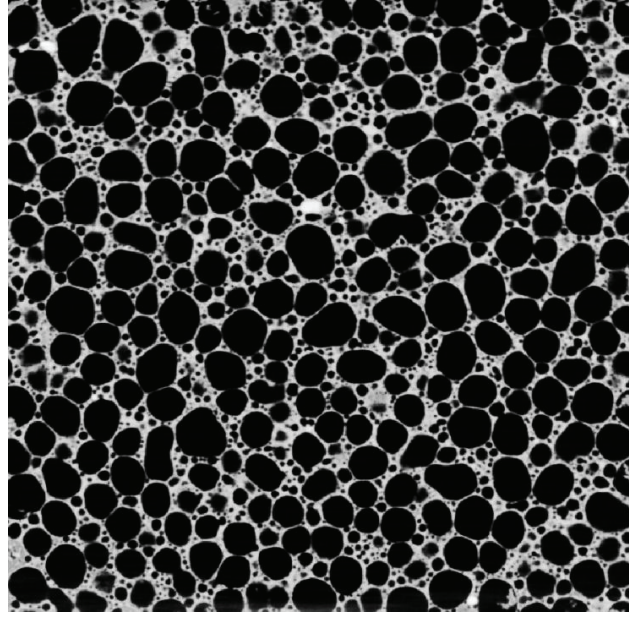

(a) Original image

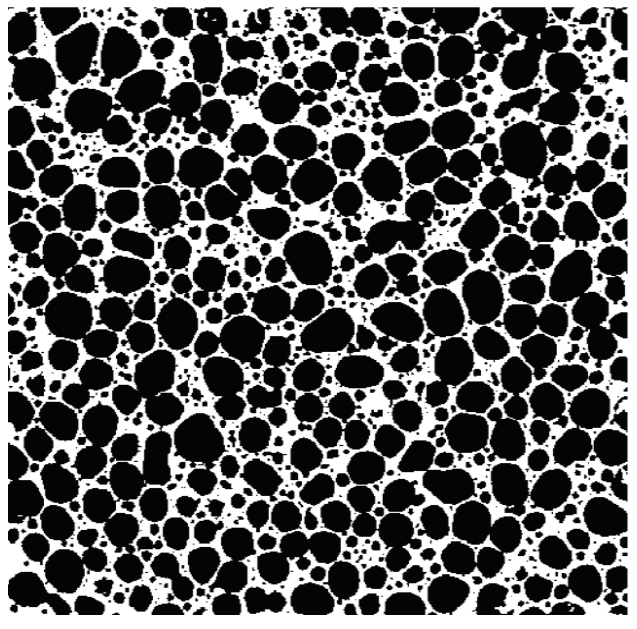

(b) Binary image

Figure 7. 2D real porous structure from the $3 \mathrm{D}$ cross-sectional XCT image. (a) Original image, (b) binary image.

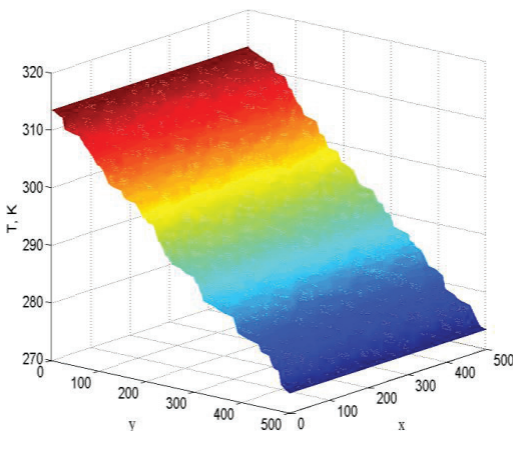

(a) $2 \mathrm{D}$ cross section structure

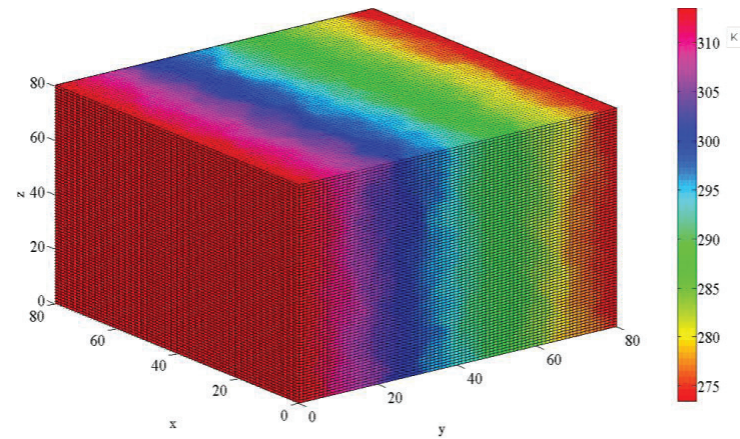

(b) 3D-XCT structure

Figure 8. Numerical calculated temperature distribution of 2D structure and 3D-XCT structure. (a) 2D crosssection structure. (b) 3D-XCT structure. 
Table 2. Predicted thermal conductivities calculated based on images with 2D and 3D modeling, using FVM.

\begin{tabular}{lccc}
\hline \multirow{2}{*}{ Structure type } & Porosity (\%) & \multicolumn{2}{c}{ Thermal conductivity $\left(\mathbf{W ~ m}^{-1} \mathbf{K}^{-1}\right)$} \\
\cline { 3 - 4 } & & FVM & Measured \\
\hline 2D & 67.24 & $0.121 \pm 0.04$ & 0.158 \\
3D & 67.22 & 0.154 & - \\
Dense material & 0 & - & 0.5 \\
\hline
\end{tabular}

The conditions for non-autoclaved aerated concrete production and thermal conductivity characterization are described in references (Esmaily \& Nuranian, 2012; Xia, Yan, \& Hu, 2013; Yang, Yan, \& Hu, 2013).

\section{CONCLUSIONS}

This work was devoted to implement $2 \mathrm{D}$ and $3 \mathrm{D}$ image-based finite volume model for analyzing the heat transfer property through a porous structure, such as non-aerated concrete. The 3D calculated value of the thermal conductivity was $0.154 \mathrm{~W} \mathrm{~m}^{-1} \mathrm{~K}^{-1}$, which is higher than the 2D predictions. However, it is in better agreement with the experimental value of $0.158 \mathrm{~W} \mathrm{~m}^{-1} \mathrm{~K}^{-1}$.

It is worth mentioning that the $2 \mathrm{D}$ calculated thermal conductivities are lower than the 3D one either using the $2 \mathrm{D}$ cross-section image. The reason for that is the heat conduction in the third direction is omitted in $2 \mathrm{D}$ simulation, leading to the underestimation of effective thermal conductivity in the same boundary conditions.

\section{ACKNOWLEDGMENTS}

Authors gratefully acknowledge the financial support from open projects from state key laboratory of high performance civil engineering materials (2010CEM002), China National Natural Science Fund of China (51178106, 51138002), Program for New Century Excellent Talents in University (NCET08-0116), 973 Program (2009CB623200), Program sponsored for scientific innovation research of college graduate in Jiangsu province(CXLX_0105). Thanks are also due to the Concrete Technology Unit, University of Dundee for providing facilities and equipments.

\section{Notation}

C Cross-sectional area across the tested sample

d Thickness of the tested sample

$k \quad$ Effective thermal conductivity $\left(\mathrm{W} \mathrm{m}^{-1} \mathrm{~K}^{-1}\right)$

$K_{3 \mathrm{D}} \quad 3 \mathrm{D}$ numerical prediction of thermal conductivity $\left(\mathrm{W} \mathrm{m}^{-1} \mathrm{~K}^{-1}\right)$

$K_{2 D} \quad 2 D$ numerical prediction of thermal conductivity $\left(\mathrm{W} \mathrm{m} \mathrm{m}^{-1} \mathrm{~K}^{-1}\right)$

$k_{\text {eff }} \quad$ Effective thermal conductivity $\left(\mathrm{W} \mathrm{m}^{-1} \mathrm{~K}^{-1}\right)$ $k_{\mathrm{f}} \quad$ Thermal conductivity of fluid phase $\left(\mathrm{W} \mathrm{m}^{-1} \mathrm{~K}^{-1}\right.$ )

$k_{\mathrm{g}} \quad$ Thermal conductivity of air $\left(\mathrm{W} \mathrm{m}^{-1} \mathrm{~K}^{-1}\right)$

$k_{\mathrm{s}} \quad$ Thermal conductivity of solid phase $\left(\mathrm{W} \mathrm{m}^{-1} \mathrm{~K}^{-1}\right)$

$X \quad$ Number of lattices along $x$-axis

$Y \quad$ Number of lattices along $y$-axis

$Z \quad$ Number of lattices along $z$-axis

$P \quad$ Number of lattices with unknown temperature

$P_{2 \mathrm{D}} \quad$ Number of 2D lattices with unknown temperature

$P_{3 \mathrm{D}} \quad$ Number of 3D lattices with unknown temperature

$Q \quad$ Time rate of heat flow (W)

$Q_{\mathrm{k}} \quad$ Heat fluxes along the $y$-axis (W)

$T$ Temperature $(\mathrm{K})$

$T_{\text {cold }} \quad$ Temperature of cold boundaries $(\mathrm{K})$

$T_{\text {hot }} \quad$ Temperature of hot boundaries (K)

$x \quad$ Coordinate along the $x$-axis

$y \quad$ Coordinate along the $y$-axis

$z \quad$ Coordinate along the $z$-axis

\section{Greek letters}

$\varepsilon \quad$ Porosity

$\lambda \quad$ Thermal conductivity, $\mathrm{W} \mathrm{m}^{-1} \mathrm{~K}^{-1}$

\section{REFERENCES}

Ahern, A., Verbist, G., Weaire, D., Phelan, R., \& Fleurent, H. (2005). The conductivity of foams: A generalisation of the electrical to the thermal case. Colloids and Surfaces A: Physicochemical and Engineering Aspects, 263, 275-279.

Aldridge, D. (2000). Foamed concrete for highway bridge works. Seminar notes on foamed concrete: Properties, applications and potential. University of Dundee, Scotland, 33-41.

Bhattacharya, A., Calmidi, V. V., \& Mahajan, R. L. (2002). Thermophysical properties of high porosity metal foams. International Journal of Heat and Mass Transfer, 45, 1017-1031.

Collishaw, P. G., \& Evans, J. R. G. (1994). An assessment of expressions for the apparent thermal conductivity of cellular materials. Journal of Materials Science, 29, 2261-2273.

EN 12664:2001. (2001). EN 12664:2001, thermal performance of building materials and productsdetermination of thermal resistance by means of guarded hot plate and heat flow meter methods-dry and moist products of medium and low thermal resistance. European Committee for Standardization.

EN 12939:2000. (2000). EN 12939:2000, thermal performance of building materials and 
products-determination of thermal resistance by means of guarded hot plate and heat flow meter methods -thick products of high and medium thermal resistance. European Committee for Standardization.

Esmaily, H., \& Nuranian, H. (2012). Non-autoclaved high strength cellular concrete from alkali activated slag. Construction and Building Materials, 26, 200-206.

Fu, X., \& Chung, D. D. L. (1999). Effect of admixtures on thermal and thermomechanical behavior of cement paste. ACI Materials Journal, 96, 455-461.

Gibson, L. J., \& Ashby, M. F. (1997). Cellular solids (2nd ed.). Cambridge, England: Cambridge University Press.

Glicksmann, L. R., \& Schuetz, M. A. (1994). In N. C. Hilyard \& A. Cunningham (Eds.), Low density cellular plastics (pp. 104-152). London, England: Chapman \& Hall.

Hashin, Z., \& Shtrikman, S. (1962). A variational approach to the theory of the effective magnetic permeability of multiphase materials. Journal of Applied Physics, 33, 3125-3131.

ISO 8990:1994. (2006). ISO 8990:1994, thermal insulation-determination of steady-state thermal transmission properties-calibrated and guarded hot box. International Standard Organization.

Jones, M. R. \& McCarthy, A. (2005a) Behaviour and assessment of foamed concrete for fill and highway applications. Proceedings of an International Conference on Uses of Foamed Concrete Global Construction: Ultimate Concrete Opportunities, Dundee, Scotland, Thomas Telford, pp. 61-88.

Kearsley, E. P., \& Mostert, H. F. (2005b) Opportunities for expanding the use of foamed concrete in the construction industry. Proceedings of an International Conference on Uses of Foamed Concrete Global Construction: Ultimate Concrete Opportunities, Dundee, Scotland. Thomas Telford, pp. 143-154.

Landauer, R. (1952). The electrical resistance of binary metallic mixtures. Journal of Applied Physics, 21, 779-784.

Litovsky, E., Shapiro, M., \& Shavit, A. (1996). Gas pressure and temperature dependances of thermal conductivity of porous materials. Part 2. Refractories and ceramics with porosity exceeding
$30 \%$. Journal of the American Ceramic Society, 79 , 1366-1376.

Lu, T. J., \& Chen, C. (1999). Thermal transport and fire retardance properties of cellular aluminium alloys. Acta Materialia, 47(5), 1469-1485.

Mydin, M. A. O., \& Wang, Y. C. (2012). Thermal and mechanical properties of lightweight foamed concrete at elevated temperatures. Magazine of Concrete Research, 64, 213-224.

Narayanan, N., \& Ramamurthy, K. (2000). Structure and properties of aerated concrete: a review. Cement and concrete composites, 22, 321-329.

Nooraini, M. Z., Ismail, A. R., Ahmad Mujahid, A. Z., et al. (2009). Foamed concrete: potential application in thermal insulation. In Malaysian Technical Universities Conference on Engineering and Technology (MUCEET 2009), 20-22 June 2009, Kuantan, Pahang.

Russell, H. W. (1935). Principles of heat flow in porous insulators. The American Ceramic Society, 18, 1-5.

Skochdopole, R. E. (1961). The thermal conductivity of foam plastics. Engineering Progress, 57(0).

Wei, S., Yiqiang, C., Yunsheng, Z., \& Jones, M. R. (2013). Characterization and simulation of microstructure and thermal properties of foamed concrete. Construction and Building Materials, 47, 1278-1291.

Wiener, O. (1904). Lamellare doppelbrechung. Phys. Z, 5, 332-338.

Xia, Y., Yan, Y., \& Hu, Z. (2013). Utilization of circulating fluidized bed fly ash in preparing non-autoclaved aerated concrete production. Construction and Building Materials, 47, 14611467.

Yang, L., Yan, Y., \& Hu, Z. (2013). Utilization of phosphogypsum for the preparation of nonautoclaved aerated concrete. Construction and Building Materials, 44, 600-606.

Yesilata, B., \& Turgut, P. (2007). A simple dynamic measurement technique for comparing thermal insulation performances of anisotropic building materials. Energy and Buildings, 39(9), 1027-1034.

Zarr, R. R. (2001). History of testing heat insulators at the National Institute of Standards and Technology. ASHRAE Transactions, 107(2), 1-11. 